\title{
As2S3 thin films deposited by atomic layer deposition
}

\section{Färm, Elina}

2017-01

Färm , E , Heikkilä , M J , Vehkamäki , M , Mizohata , K, Ritala , M , Leskelä , M \& Kemell , M 2017 , ' As2S3 thin films deposited by atomic layer deposition ' , Journal of vacuum science \& technology : an official journal of the American Vacuum Society , vol. 35 , no. 1 , 01B114 . https://doi.org/10.1116/1.4968202

http://hdl.handle.net/10138/307031

https://doi.org/10.1116/1.4968202

unspecified

acceptedVersion

Downloaded from Helda, University of Helsinki institutional repository.

This is an electronic reprint of the original article.

This reprint may differ from the original in pagination and typographic detail.

Please cite the original version. 


\title{
$\mathrm{As}_{2} \mathrm{~S}_{3}$ thin films deposited by atomic layer deposition
}

Running title: $\mathrm{As}_{2} \mathrm{~S}_{3}$ by ALD

Running Authors: Färm et al.

\author{
Elina Färm ${ }^{1,2}$, Mikko J. Heikkilä ${ }^{1}$, Marko Vehkamäki ${ }^{1}$, Kenichiro Mizohata $^{3}$, Mikko \\ Ritala ${ }^{1}$, Markku Leskelä ${ }^{1}$, Marianna Kemell ${ }^{1, a)}$ \\ ${ }^{1}$ Department of Chemistry, University of Helsinki, Fl-00014 University of Helsinki, Finland \\ ${ }^{2}$ Present address: ASM Microchemistry, Pietari Kalmin katu 1 F 2, FI-00560 Helsinki, Finland \\ ${ }^{3}$ Division of Materials Physics, Department of Physics, University of Helsinki, Fl-00014 University \\ of Helsinki, Finland \\ a) Electronic mail: marianna.kemell@helsinki.fi
}

$\mathrm{As}_{2} \mathrm{~S}_{3}$ thin films were deposited on glass and silicon (100) substrates by atomic layer deposition from tris(dimethylamino)arsine $\left.\left(\left(\mathrm{CH}_{3}\right)_{2} \mathrm{~N}\right)_{3} \mathrm{As}\right)$ and $\mathrm{H}_{2} \mathrm{~S}$. Amorphous films were deposited at an exceptionally low temperature of $50{ }^{\circ} \mathrm{C}$. No film growth was observed at higher temperatures. The films were amorphous and contained $\mathrm{H}$ and $\mathrm{C}$ as the main impurities. The refractive index was 2.3 at $1.0 \mu \mathrm{m}$. The films were sensitive to air humidity but their stability was significantly improved by a protective $\mathrm{Al}_{2} \mathrm{O}_{3}$ layer. 


\section{INTRODUCTION}

Chalcogenide glasses such as $\mathrm{As}_{2} \mathrm{~S}_{3}$ are interesting materials that have applications in many fields including photonics and phase-change memories, for example. The structure of a chalcogenide glass is a continuous random network that contains a chalcogen element $\mathrm{S}$, Se or Te and a network forming element As, Ge, P, Sb or Si. ${ }^{1}$ Band gaps of chalcogenide glasses are in the visible or near-IR region, and they are transparent to mid-IR wavelengths. Their refractive indices are between 2-3. Interest of the photonics community towards these materials is driven by their high third-order optical nonlinearities that make them suitable as waveguide materials for all-optical signal processing. ${ }^{1}$ In case of $\mathrm{As}_{2} \mathrm{~S}_{3}$, amorphous thin films have shown higher optical nonlinearities than bulk glass ${ }^{2}$, which further motivates thin film research on these materials.

Our group has earlier developed atomic layer deposition (ALD) precursors and processes for some chalcogenide glasses ${ }^{3-7}$, but the main focus at that time was on $\mathrm{Ge}-\mathrm{Sb}$ Te and related compounds for phase change memory applications ${ }^{3-7}$ and As-containing chalcogenide glasses were not studied. As far as the authors know, no ALD processes have been reported for $\mathrm{As}_{2} \mathrm{~S}_{3}$ so far.

Amorphous $\mathrm{As}_{2} \mathrm{~S}_{3}$ films have previously been prepared mostly by physical vapor deposition methods such as sputtering ${ }^{8}$, evaporation ${ }^{2,9-11}$ and pulsed laser deposition ${ }^{12,13}$. Plasma-enhanced chemical vapor deposition ${ }^{10,14}$ has been studied in a few publications. Solution-based methods include chemical bath deposition ${ }^{15}$, electrodeposition ${ }^{16}$, spincoating $^{17}$, dip-coating ${ }^{18}$ and solution casting ${ }^{19}$. Low substrate temperatures were used in 
all cases. As compared to other deposition methods, ALD has the advantage of conformal film growth which allows homogeneous films with accurate thicknesses to be grown also in $3 \mathrm{D}$ structures.

In this study we report, for the first time, an atomic layer deposition process for $\mathrm{As}_{2} \mathrm{~S}_{3}$ thin films from tris(dimethylamino)arsine $\left(\left(\mathrm{CH}_{3}\right)_{2} \mathrm{~N}\right)_{3} \mathrm{As}$ and $\mathrm{H}_{2} \mathrm{~S}$.

Tris(dimethylamino)arsine is thermally stable over a wide temperature range ${ }^{20}$, and it has been used for atomic layer epitaxy of GaAs at $450{ }^{\circ} \mathrm{C}^{21}$. We performed initial growth experiments also using $\mathrm{AsCl}_{3}$ as the As precursor, but discarded it from further studies due to its corroding attack towards the steel parts of our precursor delivery system.

\section{EXPERIMENTAL}

\section{A. $\quad A s_{2} S_{3}$ film deposition}

The $\mathrm{As}_{2} \mathrm{~S}_{3}$ films were grown in a flow-type F120 reactor (ASM Microchemistry, Ltd., Finland). The growth temperature of $50{ }^{\circ} \mathrm{C}$ was chosen on the basis of initial tests showing that the film growth occurs only in a very narrow temperature range. No film growth was observed at temperatures higher than $50^{\circ} \mathrm{C}$. Films were grown onto $5 \times 5 \mathrm{~cm}^{2}$ soda lime glass and $\mathrm{Si}(100)$ substrates. Because the deposition temperature was low, the substrates were preheated for some experiments in an oven at $100{ }^{\circ} \mathrm{C}$ for $15 \mathrm{~min}$ before loading to the reactor to ensure moisture removal from the substrate surface and prevent the formation of arsenic oxide during the first As precursor pulse. On the basis of visual inspection, preheating improved the film uniformity significantly. The films were deposited from tris(dimethylamino)arsine $\left(\left(\mathrm{CH}_{3}\right)_{2} \mathrm{~N}\right)_{3} \mathrm{As}, 99 \%$, Strem Chemicals Inc.) and $\mathrm{H}_{2} \mathrm{~S}(99.5+\%$, Aldrich). All chemical handling was done using a gas mask. The arsine 
precursor was evaporated inside the cold end of the reactor at about $19^{\circ} \mathrm{C}$ from a glass boat that had a small opening with a diameter of about $2 \mathrm{~mm}$. The flow rate of $\mathrm{H}_{2} \mathrm{~S}$ was adjusted to $7 \mathrm{sccm}$. Pulse times were $0.3-3 \mathrm{~s}$ for tris(dimethylamino)arsine and $0.3 \mathrm{~s}$ for $\mathrm{H}_{2} \mathrm{~S}$. Nitrogen purges were 1-2 s to ensure the removal of excess precursor molecules and gaseous byproducts. The process was run under a nitrogen pressure of about $10 \mathrm{mbar}$ and nitrogen was used as the carrier and purging gas.

\section{B. Protective $\mathrm{Al}_{2} \mathrm{O}_{3}$}

Because the films were sensitive to air humidity, some of them were protected with an about $100 \mathrm{~nm}$ thick $\mathrm{Al}_{2} \mathrm{O}_{3}$ layer prepared by electron beam evaporation of $\mathrm{Al}_{2} \mathrm{O}_{3}$ (99.99\%, Cerac/Materion, 2-12 mm grains).

\section{Characterization}

A Hitachi S-4800 field emission scanning electron microscope and INCA 350 Energy dispersive X-ray spectrometer (EDS) were used for studying the film morphologies, compositions and thicknesses. Film compositions and thicknesses were calculated from the EDS data using a GMR electron-probe thin film microanalysis program ${ }^{22}$. A density of $3.2 \mathrm{~g} / \mathrm{cm}^{3}$ was assumed for amorphous $\mathrm{As}_{2} \mathrm{~S}_{3}{ }^{23}$ Refractive index and band gap were estimated from a transmission measurement with a Hitachi U2000 spectrophotometer at the wavelength range of $370-1100 \mathrm{~nm}^{24,25}$. PANalytical X'Pert Pro MPD X-ray diffractometer was used for studying the crystallinity of the films. Anton Paar HTK1200N oven attachment was used for performing XRD measurements under 
nitrogen. The time-of-flight elastic recoil detection analysis (TOF-ERDA) was performed with $5 \mathrm{MV}$ tandem accelerator at the University of Helsinki using $50 \mathrm{MeV}^{127} \mathrm{I}^{9+}$ ion beam. The TOF-detector was at a $40^{\circ}$ angle from the beam direction, and the sample was tilted $20^{\circ}$ for symmetrical beam and recoil paths.

\section{RESULTS AND DISCUSSION}

\section{A. Film growth}

$\mathrm{As}_{2} \mathrm{~S}_{3}$ film growth was investigated in the temperature range from about 40 to 400 ${ }^{\circ} \mathrm{C}$. The As precursor pulse length was kept at $2 \mathrm{~s}$ and $\mathrm{H}_{2} \mathrm{~S}$ pulse at $0.3 \mathrm{~s}$ in these experiments. It was found that $\mathrm{As}_{2} \mathrm{~S}_{3}$ film could be deposited only in a very narrow temperature window around $50{ }^{\circ} \mathrm{C}$. Film growth was observed also at about $40{ }^{\circ} \mathrm{C}$, but those results are not included here because our experimental setup did not allow for sufficiently accurate and repeatable control of the deposition temperature at such low temperatures. Above $50{ }^{\circ} \mathrm{C}$ no film growth was observed besides minor growth on the backside of the substrate. This was probably CVD type growth resulting from inefficient purging of the tiny volume behind the substrate. At temperatures higher than $70^{\circ} \mathrm{C}$ no film growth was observed even on the backside of the substrates. On the other hand, when an $\mathrm{As}_{2} \mathrm{~S}_{3}$ film deposited at $50{ }^{\circ} \mathrm{C}$ was post-annealed in the ALD reactor at $80{ }^{\circ} \mathrm{C}$, it was found stable and remained unchanged on the basis of visual inspection. The growth temperature was thus chosen to be $50^{\circ} \mathrm{C}$.

The lack of growth at higher temperatures can be explained by sublimation of the growing film. Solid $\mathrm{As}_{2} \mathrm{~S}_{3}$ is not stable at high temperatures. This is reflected in the low

melting point of crystalline $\mathrm{As}_{2} \mathrm{~S}_{3}, 312{ }^{\circ} \mathrm{C}$ for the monoclinic phase ${ }^{26}$. Therefore $\mathrm{As}_{2} \mathrm{~S}_{3}$ is 
expected to sublime already at very low temperatures, especially in vacuum. In ALD, where the film grows very slowly, a (sub)monolayer at a time, it is possible that the newly formed (sub)monolayer sublimes (or desorbs) already during the subsequent purge, leaving the substrate uncovered. This is repeated during every cycle. Sublimation may have a less significant effect in other deposition methods where the growth process is continuous, but in ALD it forms a serious challenge and even seems to prevent the growth entirely at temperatures above $50{ }^{\circ} \mathrm{C}$. On the other hand, it seems that deposition of $\mathrm{As}_{2} \mathrm{~S}_{3}$ at temperatures higher than about $50{ }^{\circ} \mathrm{C}$ has not been reported with other methods either. In many cases the films have been post-annealed at temperatures below the glass transition temperature in order to improve their optical quality ${ }^{8,10,17,19}$.

The self-limiting nature of the $\mathrm{As}_{2} \mathrm{~S}_{3}$ growth process was investigated at $50{ }^{\circ} \mathrm{C}$ by varying the pulse length of the arsine precursor from $0.3 \mathrm{~s}$ to $3.0 \mathrm{~s}$. The $\mathrm{H}_{2} \mathrm{~S}$ pulse length was kept constant at $0.3 \mathrm{~s}$. Purge times were $2.0 \mathrm{~s}$ for the As precursor and $1.0 \mathrm{~s}$ for $\mathrm{H}_{2} \mathrm{~S}$. Long purging times were used for ensuring the removal of excess precursor and byproducts also because the growth temperature was close to room temperature. As seen in Fig. 1, the growth rate saturated at $0.65 \AA /$ cycle when the pulse length was $1.0 \mathrm{~s}$. Already a $0.5 \mathrm{~s}$ pulse gave a similar growth rate whereas a $0.3 \mathrm{~s}$ pulse was considered slightly inefficient.

The film thickness increased quite linearly with increasing number of ALD cycles, as can be seen in Fig. 2. The growth rate varied between 0.64 and $0.69 \AA$ /cycle throughout the experiments, further supporting the growth to be ALD type. Films deposited with 500 and 750 cycles resulted in growth rates closer to $0.60 \AA /$ cycle. When the number of cycles increased to 1000 cycles, the growth rate was $0.67 \AA /$ cycle, and 
with 1500 cycles the growth rate was $0.69 \AA /$ cycle. Some films were studied also by SEM imaging of fractured cross-sections. Film thicknesses observed by SEM were roughly in agreement with those calculated from EDS data.

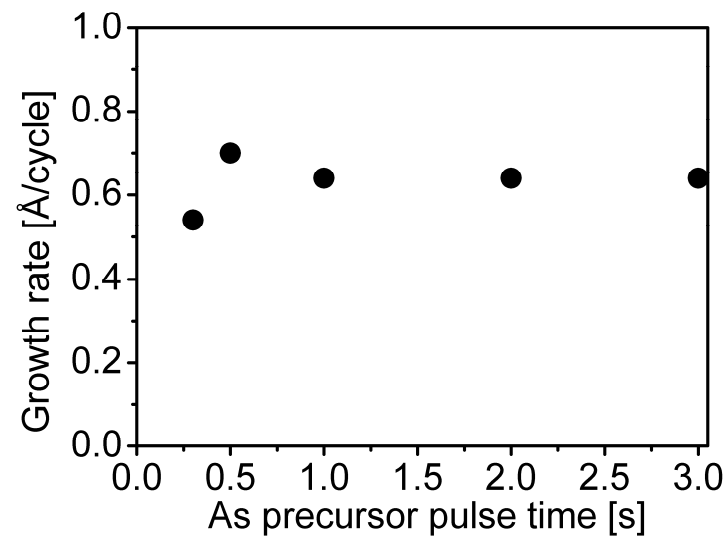

FIG. 1. Growth rate of $\mathrm{As}_{2} \mathrm{~S}_{3}$ films on silicon as a function of As precursor pulse time at $50{ }^{\circ} \mathrm{C}$. Purge time was $2 \mathrm{~s}$ in all experiments. Pulse and purge times for $\mathrm{H}_{2} \mathrm{~S}$ were $0.3 \mathrm{~s}$ and $1 \mathrm{~s}$, respectively.

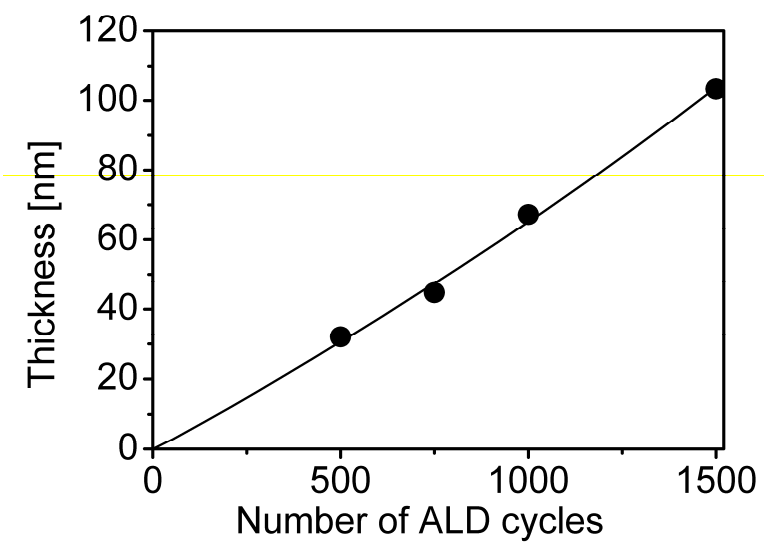

FIG. 2. Thickness of $\mathrm{As}_{2} \mathrm{~S}_{3}$ films on $\mathrm{Si}(100)$ at $50{ }^{\circ} \mathrm{C}$ as a function of the number of $\mathrm{ALD}$ cycles.

\section{B. Film properties}


The films were very smooth and almost no features could be seen with SEM. EDS was used to measure the film composition. All the films had about 40 at. $\%$ of arsenic and 60 at. $\%$ of sulfur as calculated using the GMR electron-probe thin film microanalysis program ${ }^{22}$. This confirms that the film composition is close to stoichiometric $\mathrm{As}_{2} \mathrm{~S}_{3}$. Figure 3 shows that film composition does not vary much with the growth conditions. ERDA measurement revealed a S/As molar ratio of 1.4, indicating a slightly lower than expected S content.
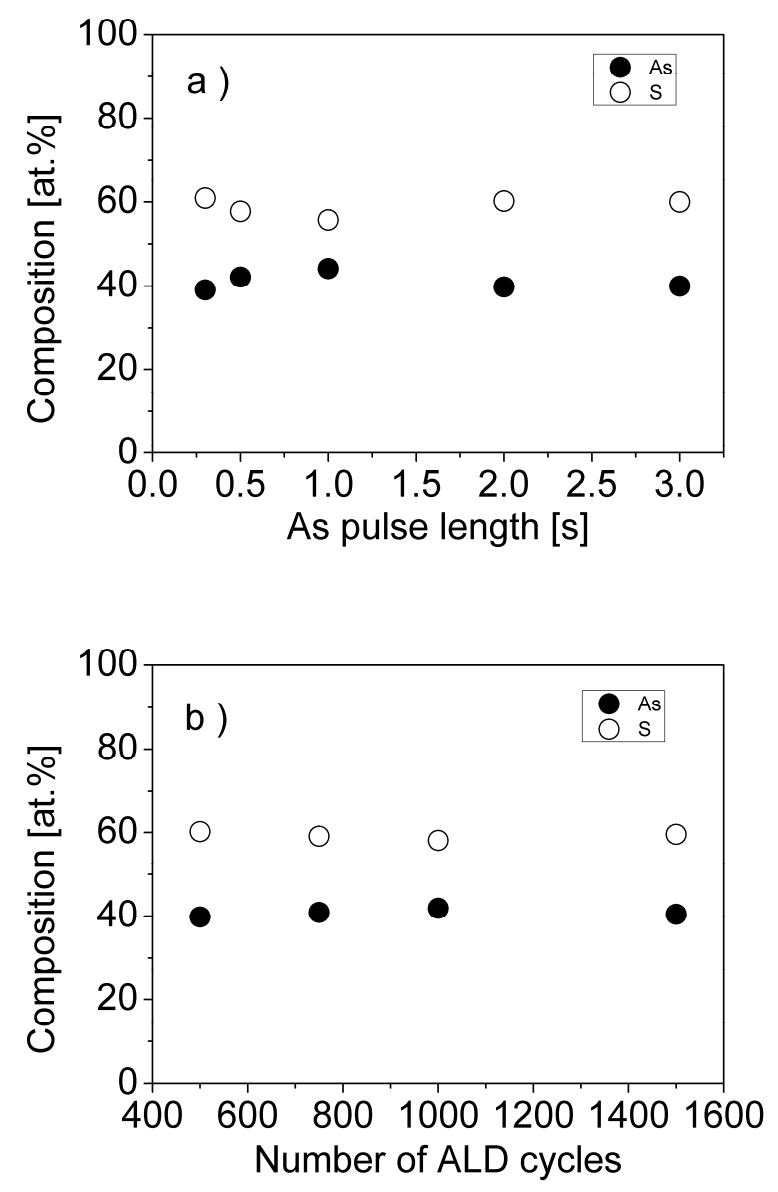

FIG. 3. Film composition as a function of a) As precursor pulse length and b) number of ALD cycles. 
$\mathrm{The} \mathrm{As}_{2} \mathrm{~S}_{3}$ films deposited by ALD were transparent and yellow colored on glass. The band gap, estimated from a UV-VIS transmission measurement for indirect transition, was around 2.1-2.4 eV. This is in agreement with values around $2.4 \mathrm{eV}$ reported in the literature for amorphous $\mathrm{As}_{2} \mathrm{~S}_{3}$ films ${ }^{8,10,11,14} . \mathrm{As}_{2} \mathrm{~S}_{3}$ is an interesting material for all optical signal processing applications and therefore its refractive index is important. Figure 4 shows the wavelength dependence of the refractive index at 520 $1100 \mathrm{~nm}$ for a film deposited on glass. The refractive indices were above 2.5 at the shorter wavelengths but decreased to below 2.3 at $1100 \mathrm{~nm}$. The values are in agreement with literature ${ }^{8,11,14}$. The refractive index of bulk crystalline $\mathrm{As}_{2} \mathrm{~S}_{3}$ (orpiment, monoclinic) is 2.40-3.02 depending on the $\mathrm{axis}^{27}$.

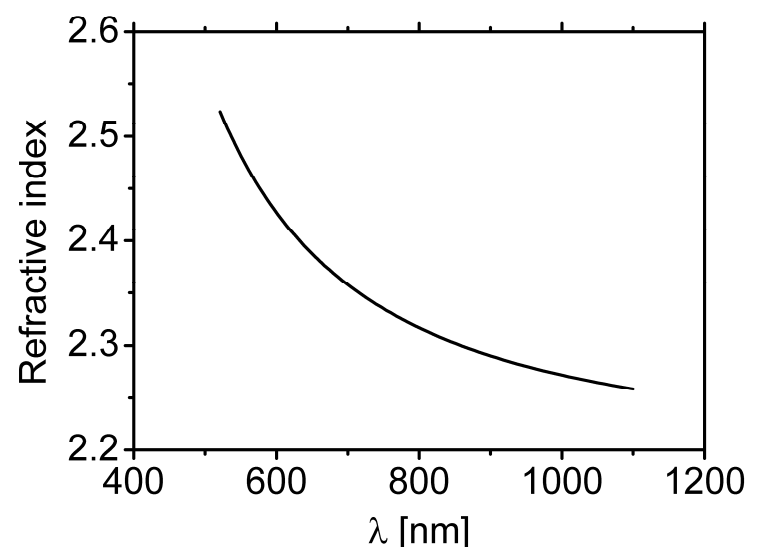

FIG. 4. Refractive index as a function of wavelength.

The films were X-ray amorphous (see Fig. 5a). Although amorphous structure is ideal for optical applications, the crystallization behavior is also interesting. However, our attempts to study the crystallization with high temperature X-ray diffraction (HTXRD) measurements under inert atmosphere failed because the film sublimed before crystallization. The absence of As and S after the experiment was verified both visually 
and with EDS measurements. To avoid sublimation, a similar experiment was performed on a film protected with an $\mathrm{Al}_{2} \mathrm{O}_{3}$ capping layer. The sample was heated slowly to $185^{\circ} \mathrm{C}$ but crystallization was not observed. Instead, the visual appearance of the film changed from smooth to grainy. SEM images (not shown) revealed that the film was badly damaged, but EDS measurements showed that at least some As and S were still left. Our results are in agreement with literature where sublimation upon annealing at $150-250{ }^{\circ} \mathrm{C}$ has been reported for films deposited by thermal evaporation ${ }^{28}$ and by chemical bath deposition ${ }^{29}$. Furthermore, $\mathrm{As}_{2} \mathrm{~S}_{3}$ is known to be very reluctant to crystallization ${ }^{30}$. In order to avoid oxidation, the X-ray diffractogram shown in Fig. 5a was measured after a minimum exposure (about $5 \mathrm{~min}$ ) to air. As can be seen from Fig. 5a, the as deposited $\mathrm{As}_{2} \mathrm{~S}_{3}$ film is mainly amorphous and no traces of crystalline $\mathrm{As}_{2} \mathrm{O}_{3}$ are present. The broad reflections around $18^{\circ}, 35^{\circ}$ and $52^{\circ}$ may originate from weakly crystalline arsenic sulfide phases. The lowest angle reflection at about $18^{\circ}$ may also be partly from the glass substrate. When exposed to air at room temperature, the film begins to oxidize as seen in Fig. 5b. Oxidation is seen also visually: the appearance of the initially uniform-colored films slowly changed to nonuniform upon prolonged exposure to ambient conditions. Fig. 5 c depicts the FWHM and intensity of the (111) reflection of cubic $\mathrm{As}_{2} \mathrm{O}_{3}$ as a function of time exposed to air. While the FWHM remains nearly constant, the intensity increases nearly linearly implying that the $\mathrm{As}_{2} \mathrm{O}_{3}$ crystallite size does not change but the number of crystallites increases during the air exposure. Crystallite sizes estimated using the Scherrer formula were some hundreds of nanometers. The calculation is complicated by the fact that the observed FWHM's are close to the instrumental broadening of the used 
parallel beam setup. SEM images (Fig. 6) also confirmed the presence of large crystals on an otherwise featureless, amorphous film. Diameters of these crystals were about $500 \mathrm{~nm}$.
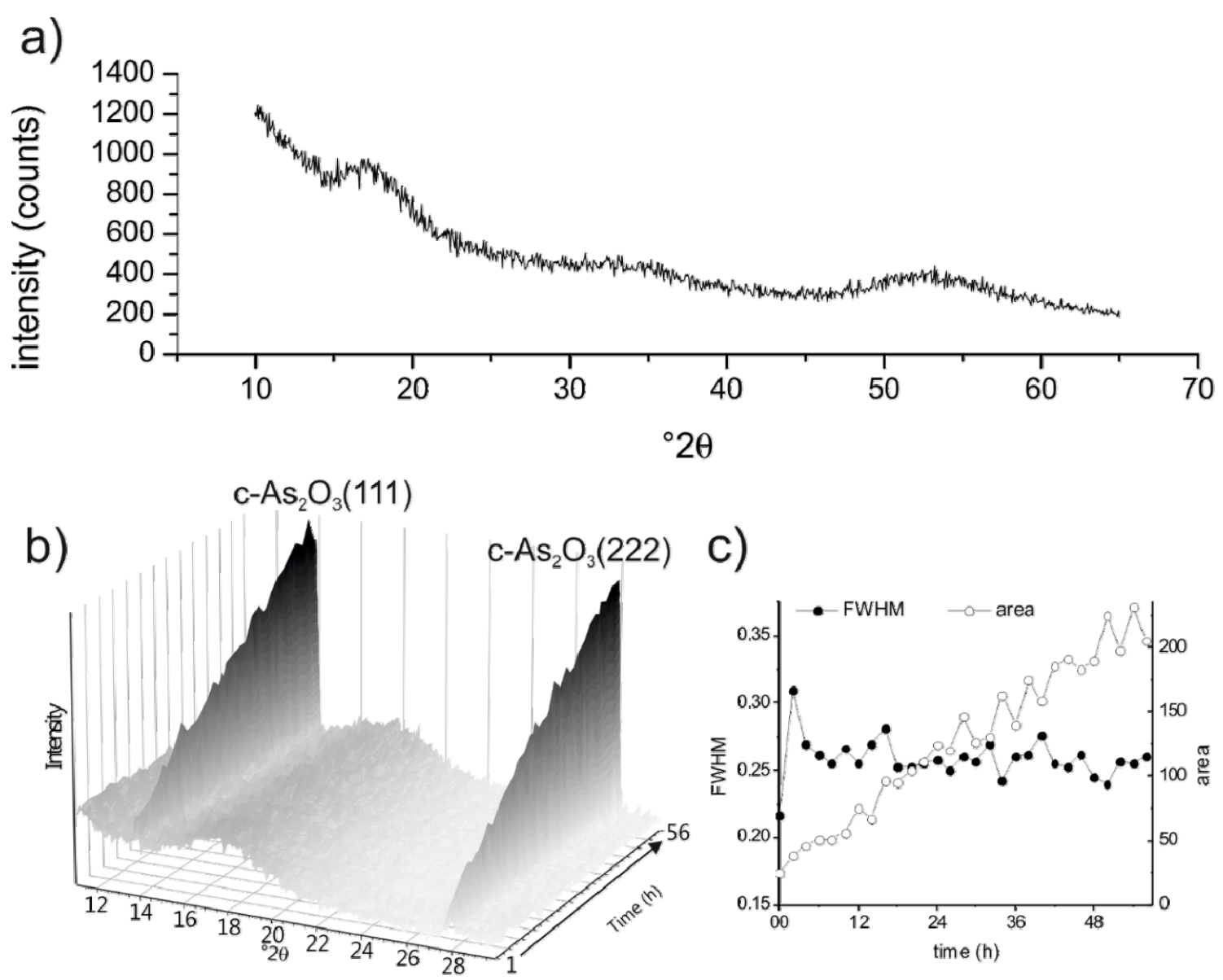

FIG. 5. a) X-ray diffractogram of an as deposited $\mathrm{As}_{2} \mathrm{~S}_{3}$ film at room temperature, b) Xray diffractograms of the $\mathrm{As}_{2} \mathrm{~S}_{3}$ film measured as a function of time when exposed to air at room temperature, c) the FWHM and area of the emerging $\mathrm{As}_{2} \mathrm{O}_{3}$ reflections in b). 

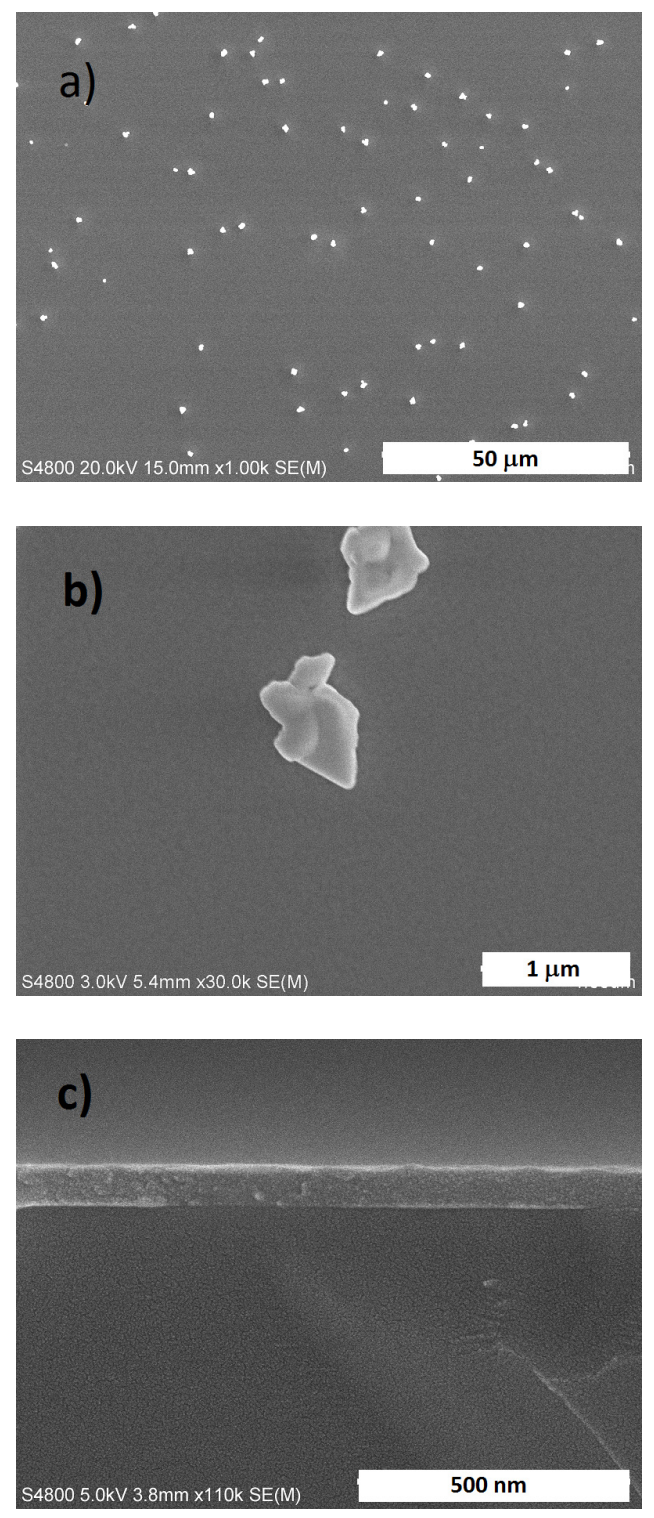

FIG. 6. SEM images of $\mathrm{As}_{2} \mathrm{~S}_{3}$ films on Si substrates: a) b) surface images with different magnifications after 1 hour exposure to air, c) a cross-section image.

EDS point measurements (Fig. 7) on the crystals showed oxygen, arsenic and sulfur as well as silicon from the substrate. On the amorphous looking area of the film no oxygen was found. A small peak of carbon (at $0.28 \mathrm{keV}$ in Fig. 7) was detected by EDS in most as-deposited films. It can originate either from the dimethylamino ligands of the 
As precursor, or from atmospheric contamination. ERDA measurements on a film protected by an evaporated $\mathrm{Al}_{2} \mathrm{O}_{3}$ layer (Fig. 8) revealed the presence of both $\mathrm{C}$ (about 6 at.\%) and $\mathrm{H}$ (about 17 at.\%) in the $\mathrm{As}_{2} \mathrm{~S}_{3}$ film. The fact that the films contain carbon and hydrogen in roughly 1:3 ratio implies the presence of methyl groups. The films also contained a small amount (about 1 at.\%) of $\mathrm{N}$. The tris(dimethylamino)arsine precursor can thus be concluded as the most likely source of the impurities. Impurities are likely to amplify the inherent instability of the film because their incorporation disturbs densification of the film structure. The presence of carbon and hydrogen impurities may thus partly explain the rapid oxidation of our films.

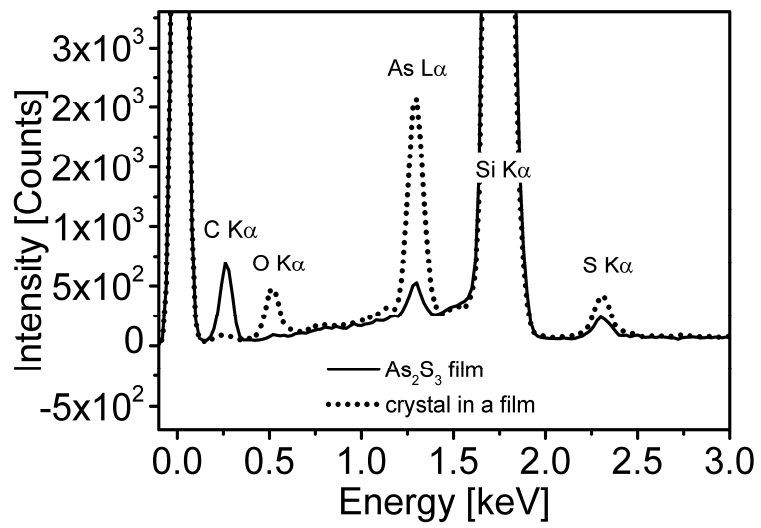

FIG. 7. EDS spectra of an $\mathrm{As}_{2} \mathrm{~S}_{3}$ film deposited at $50{ }^{\circ} \mathrm{C}$ and of an oxide crystal formed on the film upon exposure to ambient air. 


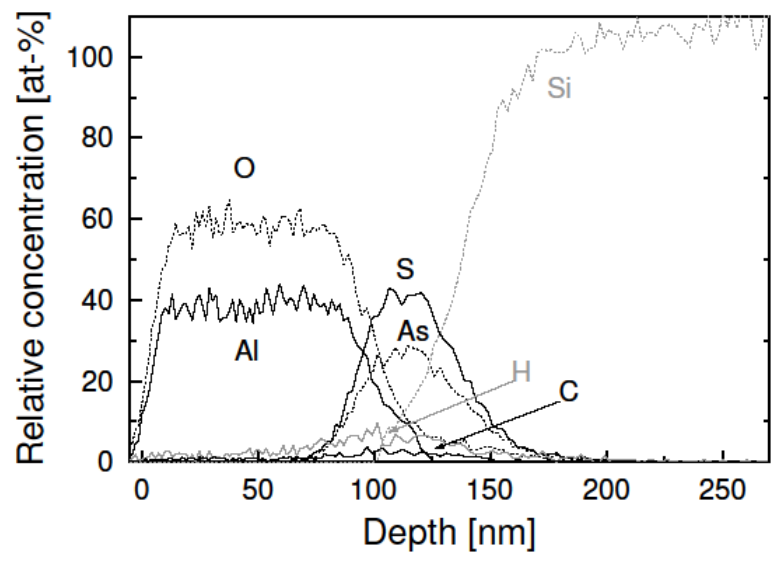

FIG. 8. TOF-ERDA depth profile of an $\mathrm{As}_{2} \mathrm{~S}_{3}$ film on silicon protected with an evaporated $\mathrm{Al}_{2} \mathrm{O}_{3}$ layer.

\section{Instability of $A s_{2} S_{3}$ in ambient conditions}

Amorphous $\mathrm{As}_{2} \mathrm{~S}_{3}$ thin films and optical fibers are known to be unstable in atmospheric conditions and our films were therefore no exception. Formation of $\mathrm{As}_{2} \mathrm{O}_{3}$ crystals on the surface of amorphous $\mathrm{As}_{2} \mathrm{~S}_{3}$ has been frequently reported in the literature ${ }^{9}$ 13,31 . This reaction naturally has a detrimental effect on the optical properties such as transmission. The formation of $\mathrm{As}_{2} \mathrm{O}_{3}$ crystals on the surface is presumably caused by air humidity $^{9,31}$, and it is significantly enhanced by illumination with sufficiently energetic light $\left(E>E_{g}\right)^{9,31}$. As regards the effect of light alone on $\mathrm{As}_{2} \mathrm{~S}_{3}$, photosensitivity and photodecomposition of amorphous $\mathrm{As}_{2} \mathrm{~S}_{3}$ have been known for decades ${ }^{31}$. These properties enable the formation of $\mathrm{As}_{2} \mathrm{~S}_{3}$ nanolenses by laser patterning ${ }^{32}$ and the use of $\mathrm{As}_{2} \mathrm{~S}_{3}$ as a photoresist to form three-dimensional $\mathrm{As}_{2} \mathrm{~S}_{3}$ microstructures ${ }^{33}$.

According to Allen et al. ${ }^{9}$, the surface oxidation mechanism involves photooxidation of As-As bonds in the $\mathrm{As}_{4} \mathrm{~S}_{4}$ moieties present in the amorphous material. In 
their studies, the formation of $\mathrm{As}_{2} \mathrm{O}_{3}$ crystals was the most efficient under simultaneous exposure to light (white LED with a sharp peak centered at $470 \mathrm{~nm}$ and broad peak at 560 $\mathrm{nm}$ ) and moisture. Illumination under lower humidity conditions caused the formation of smaller crystals, and almost no crystals were formed in the dark, regardless of the humidity level. The films of Allen et al. were $2 \mu \mathrm{m}$ thick, prepared by thermal evaporation in UHV and the exposures lasted for 21 days ${ }^{9}$. Preparation method and film thickness may have an effect: Tan et al. ${ }^{8}$ reported their amorphous magnetron sputtered films to be stable against oxidation in ambient conditions but the exposure time was not given. On the other hand, aging experiments on optical $\mathrm{As}_{2} \mathrm{~S}_{3}$ fibers by Mouawad et al. ${ }^{34}$ revealed a dramatic decrease of transmission at IR wavelengths after only a few days exposure to ambient conditions. They proposed a mechanism for the chemical aging where water adsorbed on the surface reacts with the $\mathrm{As}_{2} \mathrm{~S}_{3}$, breaking As-S-As bridges and forming As-OH and $\mathrm{H}-\mathrm{S}-\mathrm{As}$ bonds. Surface oxidation of $\mathrm{As}_{2} \mathrm{~S}_{3}$ can be prevented by protecting the samples from light and humidity either by storing them in dark and dry conditions $^{14}$ or by applying a protective coating ${ }^{34}$.

Our films were stable in air without oxide crystals for at least $5 \mathrm{~min}$. This makes it possible to coat the films after deposition with a separate process, for instance with evaporated $\mathrm{Al}_{2} \mathrm{O}_{3}$. Protection from the ambient air would ideally be done by coating the film by ALD without any exposure to air. But as the film deposition temperature is only $50{ }^{\circ} \mathrm{C}, \mathrm{Al}_{2} \mathrm{O}_{3}$ deposited by ALD at the same temperature is not an option: Purging of $\mathrm{H}_{2} \mathrm{O}$ is inefficient at low temperatures, and $\mathrm{H}_{2} \mathrm{O}$ and especially the other oxygen precursors such as $\mathrm{O}_{2}$ radicals or $\mathrm{O}_{3}$ may damage the sulfide film. To protect our amorphous films, we thus made an $\mathrm{Al}_{2} \mathrm{O}_{3}$ capping layer by electron beam evaporation. The as-deposited 
$\mathrm{As}_{2} \mathrm{~S}_{3}$ films were transferred to the evaporator as quickly as possible to minimize atmospheric exposure. Figure 9 shows two X-ray diffractograms and UV-vis transmission curves of an $\mathrm{As}_{2} \mathrm{~S}_{3}$ sample protected with the evaporated $\mathrm{Al}_{2} \mathrm{O}_{3}$ layer. The measurements were made immediately after depositing the protective layer and after the protected sample had been exposed to ambient conditions for two days. No signs of $\mathrm{As}_{2} \mathrm{O}_{3}$ are seen in either figure. The X-ray diffractograms measured before and after the exposure are practically identical. The UV-vis transmission curves in Fig. 9b) show a small difference that is probably due to inaccurate repetition of the measurement region. If the measurements are done on slightly different locations on the sample, small variations in thickness and composition become visible. Especially the thickness of the evaporated $\mathrm{Al}_{2} \mathrm{O}_{3}$ film is not perfectly homogeneous over the entire $5 \times 5 \mathrm{~cm}^{2}$ area. Continued visual inspection of protected samples showed no changes after weeks of storage in ambient conditions. Exposure to normal laboratory illumination did not seem to cause any changes either.

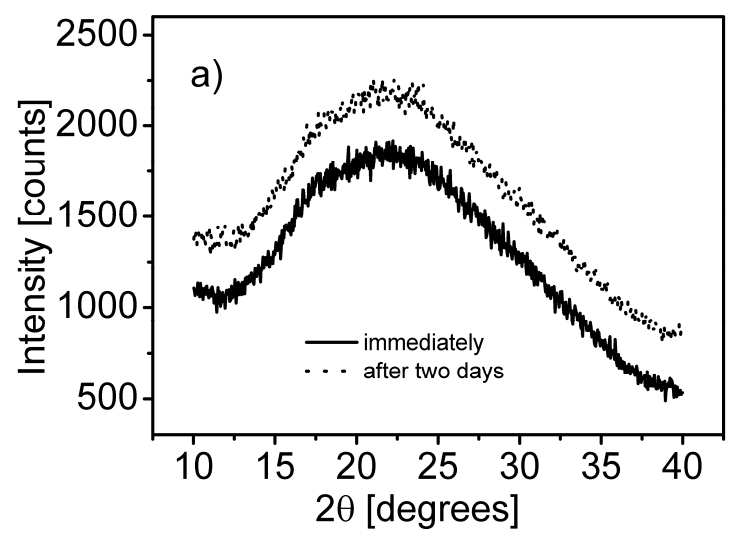




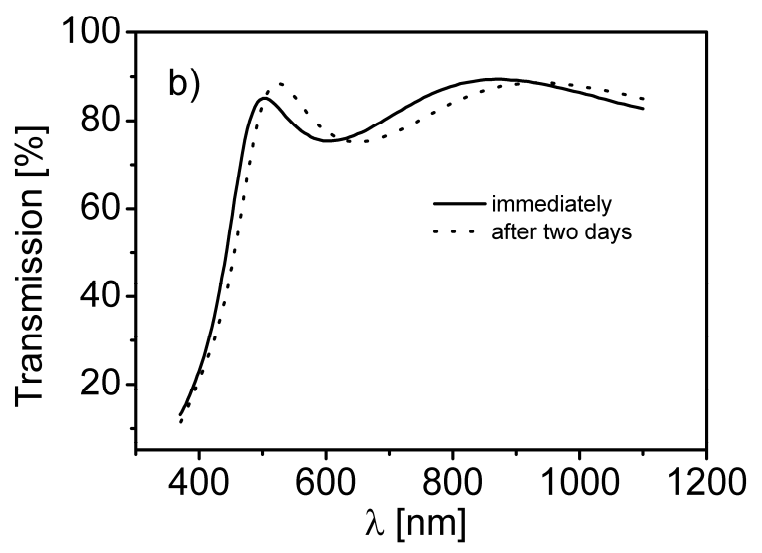

FIG. 9. a) X-ray diffractograms and b) UV-vis transmission spectra measured for an $\mathrm{As}_{2} \mathrm{~S}_{3}$ sample protected with an evaporated $\mathrm{Al}_{2} \mathrm{O}_{3}$ layer. The X-ray diffractogram measured after two days has been shifted vertically to enhance visibility.

\section{IV.SUMMARY AND CONCLUSIONS}

$\mathrm{As}_{2} \mathrm{~S}_{3}$ thin films were deposited by ALD for the first time from tris(dimethylamino)arsine and $\mathrm{H}_{2} \mathrm{~S}$ at $50{ }^{\circ} \mathrm{C}$. The $\mathrm{As}_{2} \mathrm{~S}_{3}$ films prepared by ALD exhibited properties that are favorable concerning optical applications: correct composition that was not greatly affected by deposition conditions, smooth and amorphous structure, high refractive index. The films contained $\mathrm{C}$ and $\mathrm{H}$, in atomic ratio of $1: 3$ as the main impurities. The films were sensitive to air humidity but the formation of $\mathrm{As}_{2} \mathrm{O}_{3}$ crystals was prevented by a protective $\mathrm{Al}_{2} \mathrm{O}_{3}$ layer deposited by evaporation. Attempts to crystallize the amorphous $\mathrm{As}_{2} \mathrm{~S}_{3}$ films by annealing under inert gas resulted in sublimation of the entire film. 


\section{ACKNOWLEDGMENTS}

The authors thank the Academy of Finland (grant 251142, and the Finnish Centre of Excellence in Atomic Layer Deposition) for funding.

\section{REFERENCES}

${ }^{1}$ B. J. Eggleton, B. Luther-Davies B., and K. Richardson, Nature Photon. 5, 141-148 (2011).

${ }^{2}$ S. Rani, D. Mohan, N. Kishore, and Purnima, Spectrochim. Acta A 93, 135-139 (2012).

${ }^{3}$ V. Pore, T. Hatanpää, M. Ritala, and M. Leskelä, J. Am. Chem. Soc. 131, 3478-3480 (2009).

${ }^{4}$ M. Ritala, V. Pore, T. Hatanpää, M. Heikkilä, M. Leskelä, K. Mizohata, A. Schrott, S. Raoux, and S. M. Rossnagel, Microelectron. Eng. 86, 1946-1949 (2009).

${ }^{5}$ M. Leskelä, V. Pore, T. Hatanpää, M. Heikkilä, M. Ritala, A. Schrott, S. Raoux, and S. Rossnagel, ECS Trans. 25, 399-407 (2009).

${ }^{6}$ V. Pore, K. Knapas, T. Hatanpää, T. Sarnet, M. Kemell, M. Ritala, M. Leskelä, and K. Mizohata, Chem. Mater. 23, 247-254 (2011).

${ }^{7}$ T. Sarnet, V. Pore, T. Hatanpää, M. Ritala, M. Leskelä, A. Schrott, Y. Zhu, S. Raoux, and H.-Y. Cheng, J. Electrochem. Soc. 158, D694-D697 (2011).

${ }^{8}$ W. C. Tan, M. E. Solmaz, J. Gardner, R. Atkins, and C. Madsen, J. Appl. Phys. 107, 033524 (2010).

${ }^{9}$ P. J. Allen, B. R. Johnson, R. T. Baran, N. C. Anheier, S. K. Sundaram, M. H. Engelhard, and B. T. Broocks, Phys. Chem. Glasses: Eur. J. Glass Sci. Technol. B 47, 681-687 (2006).

${ }^{10}$ P. Nagels, R. Mertens, and L. Tichy, Mater. Lett. 57, 2494-2500 (2003).

${ }^{11}$ E. R. Shaaban, Mater. Chem. Phys. 100, $411-417$ (2006). 
${ }^{12}$ R. P. Wang, S. J. Madden, C. J. Zha, A. V. Rode, and B. Luther-Davies, J. Appl. Phys. 100, 063524 (2006).

${ }^{13}$ D.-Y. Choi, S. Maden, A. Rode, R. Wang, and B. Luther-Davies, J. Non-Cryst. Solids 354, 3179-3183 (2008).

${ }^{14}$ J. M. González-Leal, R. Prieto-Alcón, M. Vlcek, E. Márquez, J. Non-Cryst. Solids 345\&346, 88-92 (2004).

${ }^{15}$ A. U. Ubale, J. S. Kantale, D. M. Choudhari, V. N. Mitkari, M. S. Nikam, and M. R. Belkhedkar, Thin Solid Films 542, 160-166 (2013).

${ }^{16}$ N. S. Yesugade, C. D. Lokhande, and C. H. Bhosale, Thin Solid Films 263, 145-149 (1995).

${ }^{17}$ S. Song, J. Dua, and C. B. Arnold, Opt. Express 18, 5472-5480 (2010).

${ }^{18}$ V. Matějec, J. Pedliková, I. Barton, J. Zavadil, and P. Kostka, J. Non-Cryst. Solids 431, 47-51 (2016).

${ }^{19}$ C. Tsay, E. Mujagić, C. K. Madsen, C. F. Gmachl, and C. B. Arnol, Opt. Express 18, 15523-15530 (2010).

${ }^{20}$ S. Salim, C. K. Lim, and K. F. Jensen, Chem. Mater. 7, 507-516 (1995).

${ }^{21}$ K. Fujii, I. Suemune, T. Koui, and M. Yamanishi, Appl. Phys. Lett. 60, 1498 (1992).

${ }^{22}$ R. A. Waldo, Microbeam Anal. 1988, 310-314.

${ }^{23}$ K. Tanaka, and K. Shimakawa, Amorphous Chalcogenide Semiconductors and Related Materials, Springer, 2011, p. 64.

${ }^{24}$ M. Ylilammi, and T. Ranta-aho, Thin Solid Films 232, 56-62 (1993).

${ }^{25}$ M. Sreemany, and S. Sen, Mater. Chem. Phys. 83, 169-177 (2004).

${ }^{26} C R C$ Handbook of chemistry and physics, $96{ }^{\text {th }}$ edition $2015-2016$, p. 4-49.

${ }^{27} C R C$ Handbook of chemistry and physics, $96^{\text {th }}$ edition 2015-2016, p. 4-142.

${ }^{28}$ D.-Y. Choi, S. Madden, D. Bulla, R. Wang, A. Rode, and B. Luther-Davies, J. Appl. Phys. 107, 053106 (2010). 
${ }^{29}$ Y. Peña-Méndez, M.; T. S. Nair, and P. K. Nair, Semicond. Sci. Technol. 21, 450-461 (2006).

${ }^{30}$ Tanaka, K.; Shimakawa, K. Amorphous Chalcogenide Semiconductors and Related Materials, Springer, 2011, p. 70.

${ }^{31}$ J. S. Berkes, S. W. Jr. Ing, and W. J. Hillegas, J. Appl. Phys. 42, 4908 (1971).

${ }^{32}$ A. Velea, M. Popescu, F. Sava, A. Lőrinczi, I. D. Simandan, G. Socol, I. N. Mihailescu, N. Stefan, F. Jipa, M. Zamfirescu, A. Kiss, and V. Braic, J. Appl. Phys. 112, 033105 (2012).

${ }^{33}$ S. H. Wong, M. Thiel, P. Brodersen, D. Fenske, G. A. Ozin, M. Wegener, and G. von Freymann, Chem. Mater. 19, 4213-4221 (2007).

${ }^{34}$ O. Mouawad, C. Strutynski, J. Picot-Clémente, F. Désévédavy, G. Gadret, J-C. Jules, and F. Smektala, Opt. Mater. Express 4, 2190-2203 (2014).

\section{FIGURE CAPTIONS}

FIG. 1. Growth rate of $\mathrm{As}_{2} \mathrm{~S}_{3}$ films on silicon as a function of As precursor pulse time at $50{ }^{\circ} \mathrm{C}$. Purge time was $2 \mathrm{~s}$ in all experiments. Pulse and purge times for $\mathrm{H}_{2} \mathrm{~S}$ were $0.3 \mathrm{~s}$ and $1 \mathrm{~s}$, respectively.

FIG. 2. Thickness of $\mathrm{As}_{2} \mathrm{~S}_{3}$ films on $\mathrm{Si}(100)$ at $50{ }^{\circ} \mathrm{C}$ as a function of the number of ALD cycles.

FIG. 3. Film composition as a function of a) As precursor pulse length and b) number of ALD cycles.

FIG. 4. Refractive index as a function of wavelength.

FIG. 5. a) X-ray diffractogram of an as deposited $\mathrm{As}_{2} \mathrm{~S}_{3}$ film at room temperature, b) Xray diffractograms of the $\mathrm{As}_{2} \mathrm{~S}_{3}$ film measured as a function of time when exposed to air at room temperature, c) the FWHM and area of the emerging $\mathrm{As}_{2} \mathrm{O}_{3}$ reflections in $\mathrm{b}$ ). 
FIG. 6. SEM images of $\mathrm{As}_{2} \mathrm{~S}_{3}$ films on Si substrates: a) b) surface images with different magnifications after 1 hour exposure to air, c) a cross-section image.

FIG. 7. EDS spectra of an $\mathrm{As}_{2} \mathrm{~S}_{3}$ film deposited at $50{ }^{\circ} \mathrm{C}$ and of an oxide crystal formed on the film upon exposure to ambient air.

FIG. 8. TOF-ERDA depth profile of an $\mathrm{As}_{2} \mathrm{~S}_{3}$ film on silicon protected with an evaporated $\mathrm{Al}_{2} \mathrm{O}_{3}$ layer.

FIG. 9. a) X-ray diffractograms and b) UV-vis transmission spectra measured for an $\mathrm{As}_{2} \mathrm{~S}_{3}$ sample protected with an evaporated $\mathrm{Al}_{2} \mathrm{O}_{3}$ layer. The X-ray diffractogram measured after two days has been shifted vertically to enhance visibility. 